\title{
O Self que (não) fala: um modelo baseado em identidades sobre voz e silêncio de empregados
}

BRUNO FELIX ${ }^{1}$

${ }^{1}$ Fucape Business School / Programa de Pós-Graduação em AdMinistração, Vitória - ES, BrasiL

Resumo

A literatura sobre voz e silêncio de empregados tem apresentado tais comportamentos como motivados por propósitos calculativosinstrumentais (o que eu ganharei/perderei se eu falar?). Eu defendo que voz e silêncio são comportamentos sociofuncionais inseridos em interações do cotidiano no trabalho e me fundamento na teoria da identidade social para propor um modelo baseado em identidades sobre a voz e silêncio de empregados (como falar afeta minha definição de quem sou?). O modelo apresentado explica como indivíduos podem falar ou se manter em silêncio ao preservar ou reestruturar seu senso de self diante de ameaças a identidades. Eu também exploro as condições para cada comportamento de voz baseado em identidades e apresento contribuições para as literaturas sobre voz e silêncio nos campos do Comportamento Organizacional e das Relações Industriais.

Palavras-chave: Voz. Silêncio. Identidade. Ameaça. Self.

\section{The (un)speaking self: an identity-based model for employee voice and silence}

\section{Abstract}

The literature on employee voice and silence has typically explored these behaviors as being motivated by calculative-instrumental purposes (what will I gain/lose if I volunteer information?). I argue that voice and silence are social-functional behaviors that are embedded within everyday interactions at work, and I draw on social identity theory to propose an identity-based model of employee voice and silence (how does speaking up affect my definition of who l am?). The presented model explains how individuals can volunteer information or remain silent by preserving or restructuring their sense of self in the face of identity threats. I also explore the conditions for each identity-based speaking behavior and offer contributions to both the Organizational Behavior and Industrial Relations literature on employee voice and silence.

Keywords: Voice. Silence. Identity. Threat. Self.

\section{El self que (no) habla: un modelo basado en la identidad de la voz y el silencio de los empleados}

\section{Resumen}

La literatura sobre la voz y el silencio de los empleados ha presentado un comportamiento motivado por propósitos instrumentales calculadores (¿qué ganaré/perderé si hablo?). Sostengo que la voz y el silencio son comportamientos sociofuncionales integrados a las interacciones cotidianas en el trabajo, y me fundamento en la teoría de la identidad social para proponer un modelo basado en la identidad de la voz y el silencio de los empleados (¿cómo afecta el habla a mi definición de quién soy?). El modelo presentado explica cómo las personas pueden hablar o permanecer en silencio mientras preservan o reestructuran su sentido de identidad frente a amenazas a las identidades. También exploro las condiciones para cada comportamiento de voz basado en la identidad y presento contribuciones a la literatura sobre voz y silencio en los campos de comportamiento organizacional y relaciones industriales.

Palabras clave: Voz. Silencio. Identidad. Amenaza. Self. 


\section{INTRODUÇÃO}

Organizações contemporâneas são frequentemente desafiadas a responderem de forma rápida e adequada a cenários de complexidade e mudança (BUDD, 2014). Neste contexto, criar uma força de trabalho que compartilhe informormações e ideias de maneira fluida torna-se um uma fonte importante para o alcance de vantagens competitivas (WILKINSON e FAY, 2011). Aprimorar este fluxo de compartilhamento de ideias permite que organizações ofereçam melhores respostas a demandas ambientais, se ajustem a forças contingenciais e melhorem a tomada de decisões (FRAZIER e FAINSCHMIDT, 2012). Além disso, é importante desenvolver ambientes de trabalho em que empregados se sintam confortáveis para expressarem suas insatisfações com injustiças no trabalho (PINDER e HARLOS, 2001). Desta forma, torna-se esperado o fato de que gestores e acadêmicos têm aumentado seu interesse em compreender os fatores que promovem e inibem a disposição de trabalhadores para compartilharem informações no trabalho (MORRISON, 2011; VAN DYNE, ANG e BOTERO, 2003).

Entretanto, expressar a voz no trabalho não é uma ação livre de riscos (DETERT e EDMONDSON, 2011). Por essa razão, uma parte relevante da literatura sobre voz e silêncio nos campos do Comportamento Organizacional (CO) e das Relações Industriais (RI) tem adotado uma abordagem instrumental/calculativa para compreender este fenômeno (p.e., DETERT e BURRIS, 2007; DETERT e TREVIÑO, 2010; LEPINE e VAN DYNE, 2001; MORRISON, 2011). No entanto, expressar-se no trabalho é uma faca de dois gumes. Por um lado, empregados podem possuir o interesse de obter ganhos organizacionais, grupais ou individuais por meio de participação e engajamento (CHAMBERLIN, NEWTON e LEPINE, 2018; MORRISON, 2011). Mas por outro, indivíduos podem questionar se seus esforços adicionais serão recompensados e, assim, tendem a avaliar os riscos de que a expressão de suas ideias gere insatisfações em outras pessoas ou grupos (BURRIS, DETERT e CHIABURU, 2008). Desta forma, a decisão pela voz no ambiente de trabalho é frequentemente abordada como sendo de natureza calculativa, instrumental, e que envolve uma avaliação da relação entre risco e retorno.

Este estudo adota uma perspectiva distinta sobre o tema de voz e silêncio no trabalho ao explorar o papel das identidades dos indivíduos em sua decisão de expressar ou não informações relevantes no trabalho. Embora eu reconheça a relevância e a plausabilidade da abordagem calculativa-instrumental, eu sustento a ideia de que voz e silêncio são apenas parcialmente explicadas por essa lente (KLAAS, OLSON-BUCHANAN and WARD, 2012). Proponho que além de se perguntarem se perderão ou ganharão algo por expressarem suas vozes no trabalho, trabalhadores também se questionam, de forma intuitiva de que forma expressar-se pode afetar seu senso de autovalor em situações do cotidiano (ASHFORD e BARTON, 2007). Argumento que a voz e o silêncio de trabalhadores são comportamentos que também são motivados por questões sociais as quais tanto podem levar à preservação como à reestruturação de identidades no âmbito das relações profissionais (PETRIGLIERI, 2011).

Assim, neste trabalho, objetivo desenvolver um modelo baseado em identidades sobre voz e silêncio de empregados. No modelo apresentado, voz e silêncio são vistos como construídos em relações rotineiras, de nível micro (LAM, REES, LEVESQUE et al., 2018) e apresentados como respostas antecipatórias para lidar com ameaças às suas identidades decorrentes do possível ato de verbalizarem ideias relevantes no trabalho. A literatura sobre voz e silêncio no trabalho pode se beneficiar da adoção desta abordagem baseada em identidades uma vez que ela permite uma análise da decisão de (não) compartilhar informações no trabalho sob a luz de um motive inexplorado: o senso de autovalor de indivíduos (SLUSS e ASHFORTH, 2007). Portanto, este estudo preenche uma lacuna na literatura sobre voz e silêncio ao incluir a lente de identidades na lista dos determinantes para a voz (KAUFMAN, 2015; KLAAS, OLSON-BUCHANAN e WARD, 2012; MORRISON, 2011).

\section{REVISÃO DA LITERATURA}

\section{Voz e silêncio de empregados: uma revisão}

A voz e o silêncio de empregados são definidos na literatura de duas formas principais e diferentes, ainda que haja um consenso de que voz se refira a uma 'oportunidade de se expressar', enquanto silêncio seja o oposto (MOWBRAY, WILKINSON e TSE, 2014). No contexto das Relações Industriais (RI) e do Comportamento Organizacional (CO), esses conceitos são tratados de formas distintas. Na literatura de RI, o ato de vocalizar é construído no nível dos sistemas organizacionais, e se refere a manifestar insatisfações com o intuito de proteger os interesses dos empregados (KAUFMAN, 2015). Essa forma de voz tende a ser formal, e pró-social (KLAAS, OLSON-BUCHANAN e WARD, 2012). Por sua vez, a literatura sobre CO vê a voz como uma 
decisão individual de expressar ideias para beneficiar a organização (MORRISON, 2011). De forma oposta, na literatura sobre $\mathrm{RI}$, a voz é interpretada como o ato de não expressar formalmente assuntos pró-sociais que poderiam preservar os interesses dos empregados (FELIX, MELLO e VON BORELL, 2018). Na literatura sobre CO, por outro lado, vê-se o silêncio como uma decisão individual de reter informações relevantes que poderiam melhorar o desempenho organizacional (KAUFMAN, 2015). Neste sentido, a voz tende a ser mais informal e a focar no aperfeiçoamento organizacional ou no funcionamento de uma unidade (LAM, REES, LEVESQUE et al., 2018). Neste estudo, adoto a perspectiva do CO para voz e silêncio, o que é explicado em maiores detalhes no próximo tópico. Tais diferenças são sumarizadas na tabela 1 (MOWBRAY, WILKINSON e TSE, 2014. p. 4).

Quadro 1

Comparando as conceitualizações de voz de empregados em RI e CO

\begin{tabular}{|c|c|c|}
\hline Literatura & $\begin{array}{l}\text { Gestão de recursos humanos/ } \\
\text { relações industriais }\end{array}$ & Comportamento organizacional \\
\hline Forma & Sistema & Comportamento \\
\hline Motivo & Insatisfação pré-social & Justiça pró-social \\
\hline Expectativa & $\begin{array}{l}\text { Interno ao papel } \\
\text { Externo ao papel }\end{array}$ & $\begin{array}{l}\text { Externo ao papel } \\
\text { Interno ao papel }\end{array}$ \\
\hline Beneficiário & $\begin{array}{l}\text { Empregado } \\
\text { Organização }\end{array}$ & Organização \\
\hline Mecanismo & Formal & Informal \\
\hline Conteúdo e tipos & $\begin{array}{l}\text { Participação baseada em tarefas } \\
\text { Solução de problemas de baixo para cima }\end{array}$ & $\begin{array}{l}\text { Sugestão para mudanças e melhoria } \\
\text { Expressão de preocupações a respeito de } \\
\text { temas danosos à organização }\end{array}$ \\
\hline Foco & $\begin{array}{l}\text { Procedimento de queixa } \\
\text { Participação na tomada de decisões }\end{array}$ & $\begin{array}{l}\text { Comunicação de diferentes ponto de vista } \\
\text { Melhora organizacional ou do } \\
\text { funcionamento da unidade }\end{array}$ \\
\hline
\end{tabular}

Fonte: Elaborado pelo autor.

\section{Voz e silêncio de empregados à luz do presente estudo}

Voz é definida neste estudo como uma comunicação formal ou informal de ideias, questionamentos, opiniões ou sugestões que pode ocorrer com o intuito de melhorar o funcionamento organizacional e/ou levantar questionamentos que são independentes dos interesses organizacionais (BURRIS, DETERT e CHIABURU, 2008; DETERT e TREVIÑO, 2010; TANGIRALA e RAMANUJAM, 2008). Embora seja um comportamento discricionário, a voz não ocorre em um vácuo, mas no âmbito de um sistema mais amplo de crenças, posições sociais e mecanismos que fomentam ou inibem sua expressão (FELIX, MELLO e VON BORELL, 2018). Por sua vez, defino silêncio como a retenção de tal comunicação e a negação por compartilhar informações relevantes (BRINSFIELD, 2013; GREENBERG e EDWARDS, 2009; MORRISON e MILLIKEN, 2000; TANGIRALA e RAMANUJAM, 2008; WANG e HSIEH, 2013). Em ambos os casos, refiro-me a comunicações verticais e horizontais. O conteúdo do que (não) é dito pode incluir diferentes formas de informações críticas relacionadas ao trabalho (TANGIRALA e RAMANUJAM, 2008), como denúncia de maus comportamentos (PINDER e HARLOS, 2001) ou injustiça (NG e FELDMAN, 2012), uma opinião dissidente ou uma sugestão para melhorar o desempenho organizacional (DUTTON e ASHFORD, 1993).

As definições apresentadas para voz e silêncio dos funcionários retratam ambos os dois como comportamentos opostos, mas há controvérsia em torno dessa questão na literatura. Meu entendimento está alinhado com outros estudos (p.e., DONAGHEY, CULLINANE, DUNDON et al., 2011; MORRISON, 2011; MORRISON, WHEELER-SMITH e KAMDAR, 2011; TANGIRALA e RAMANUJAM, 2008), nos quais a decisão de expressar potencialmente informação relevante (voz) é o oposto de optar por retê-la (silêncio), ou seja, um alto nível de voz está associado a um baixo nível de silêncio e vice-versa (MORRISON, 2011). No entanto, alguns estudiosos argumentam que, embora a voz seja uma escolha proativa, o silêncio pode ser uma resposta padrão ou um estado habitual; como tal, devem ser tratados como construtos separados (BRINSFIELD, 2013; PINDER e HARLOS, 2001; VAN DYNE, ANG e BOTERO, 2003). Morrison (2011) sugeriu que a maioria das definições de silêncio inclui a retenção intencional de informações e não a falta passiva de fala (HARVEY, MARTINKO e DOUGLAS, 2009; MORRISON e MILLIKEN, 
2000; WANG e HSIEH, 2013). Desse modo, vejo voz e silêncio como lados diferentes da mesma moeda (ASHFORD, SUTCLIFFE e CHRISTIANSON, 2009; CULLINANE e DONAGHEY, 2014).

\section{Motivações para a voz e o silêncio de empregados: o que sabemos até aqui?}

Como este artigo tem como objetivo apresentar um modelo baseado em identidade para voz e silêncio no trabalho, é importante revisar como a literatura tem explorado os diferentes motivos que os indivíduos têm para tais comportamentos. Uma suposição comum na literatura sobre CO e RI é que o motivo principal da voz é remover a insatisfação por meio da melhoria da organização. Uma vez que expressar seus pensamentos é um comportamento arriscado, os indivíduos ponderam sobre as consequências da decisão de oferecer informações confidenciais. Assim, a maioria dos estudos que analisam os motivos da voz e do silêncio dos funcionários adotou uma perspectiva instrumental calculista (p.e., BURRIS, 2012; DETERT e BURRIS, 2007). Entretanto, outros estudos também exploraram explicações além das explicações calculistas/instrumentais para esses comportamentos (ASHFORD e BARTON, 2007; DETERT e EDMONDSON, 2011).

Estudos desenvolvidos sob a perspectiva de motivos instrumentais/calculativos para a voz e o silêncio dos funcionários enfatizam duas questões principais (MORRISON, 2011). Primeiro, eles se concentram nas avaliações do indivíduo sobre a probabilidade da eficácia de expressar seus pensamentos (eficácia percebida da voz), e isso significa que os indivíduos se perguntam se o alvo ouvirá e usará as informações fornecidas para fazer as alterações ou melhorias relacionadas ao que foi expresso (DETERT e BURRIS, 2007). Quando os funcionários, nesse processo de avaliação, experimentam sentimentos de inutilidade (PINDER e HARLOS, 2001) e interpretam que falar não resultará em serem ouvidos, tendem a adotar um "silêncio aquiescente" (KNOLL e VAN DICK, 2013; VAN DYNE, ANG e BOTERO, 2003). Tais estudos se baseiam em suposições da teoria clássica da motivação de Vroom (1964), segundo a qual os esforços estão relacionados a crenças de expectativas.

Segundo, tais motivos enfatizam as avaliações que indivíduo fazem sobre a probabilidade de obter resultados negativos em decorrência ao ato de falar (segurança percebida da voz), o que sugere que os funcionários questionem se expressar seus pensamentos pode gerar retaliação e punição. Alguns exemplos seriam prejudicar sua avaliação de desempenho, ou gerar outros custos relacionados à carreira, como perder uma promoção ou ser demitido (WHITESIDE e BARCLAY, 2013). Nesse caso, confiança e medo são as forças motrizes que levam a comportamentos de voz e silêncio, e a segurança psicológica é frequentemente retratada como mediadora entre o comportamento de voz e seus antecedentes (CULLINANE e DONAGHEY, 2014).

Argumento que a decisão de falar e a maneira de falar no trabalho são influenciadas por processos psicológicos menos intencionais de gerenciamento de identidade individual. Para fornecer suporte conceitual ao meu argumento, a seguir, utilizo a literatura existente para explicar como defino a identidade neste artigo, por que os eventos que ocorrem quando os indivíduos questionam se devem falar são percebidos como ameaças à identidade e o que se sabe sobre como os indivíduos reagem a tais situações.

\section{Identidade social e voz e silêncio de empregados}

\section{Definindo identidade}

O modelo apresentado baseia-se na ideia de que as interações no local de trabalho oferecem um estímulo à ativação identitária (ASHFORTH, 2001; LEAVITT e SLUSS, 2015; FELIX e CAVAZOTTE, 2019) e que situações no cotidiano organizacional, incluindo as opções para (não) falar, são navegados pelo self social (HOGG e TERRY, 2000). Como existem muitas abordagens distintas para o estudo da identidade (PRATT e FOREMAN, 2000; GOMES e FELIX, 2019), defino o que quero dizer com o termo 'identidade' no contexto deste estudo. Primeiro, concentro-me apenas nas identidades individuais (ou auto); e não exploro identidades mantidas por um grupo ou por uma coletividade neste artigo.

Segundo, identidades refletem a consistência em termos de como as pessoas pensam, agem e sentem sobre si mesmas. Elas funcionam como estruturas implícitas de significado que norteiam a compreensão do mundo adotada por um indivíduo (BREWER e GARDNER, 1996; FELIX e CAVAZOTTE, 2019). Eles também servem para satisfazer nossa necessidade de nos vermos de uma maneira positiva (DUTTON, ROBERTS e BEDNAR, 2010). As identidades ajudam os indivíduos a alcançar algum nível de estabilidade emocional e cognitiva necessárias para interagirem nas relações de trabalho (COOPER e THATCHER, 2010). 
Terceiro, embora as identidades ofereçam estabilidade ao senso de self, essas definições não são particularmente estáveis ou homogêneas; os indivíduos desenvolvem um conjunto de possíveis eus distintos e escolhem as identidades específicas que parecem gerar resultados mais apropriados no contexto de interações específicas que desenvolvem no trabalho (CONROY e O'LEARY-KELLY, 2014). Assim, as identidades individuais são maleáveis (ver maleabilidade da identidade; MARKUS e WURF, 1987; PETRIGLIERI, 2011; CONROY e O'LEARY-KELLY, 2014), possuem caráter múltiplo e dinâmico e são constantemente avaliadas por meio de interações sociais. Nesse processo, indivíduos conferem diferentes níveis de importância a identidades distintas. Essa propriedade, denominada saliência de identidade, refere-se à importância central de uma identidade para seu selso de self e sugere que indivíduos tendem a fazer escolhas razoavelmente consistentes quando confrontados com situações conflituosas ao longo do tempo (ASHFORTH, 2001).

Quarto, as identidades são suscetíveis à influência das proscrições sociais (ver WEAVER e AGLE, 2002) porque o eu reflete a sociedade; o senso de autoestima é construído socialmente (MEAD, 1934). Assim, como indivíduos refletem a sociedade (estrutura) e fazem escolhas (agência), é possível ver que indivíduos diferentes mostram níveis distintos de internalização de proscrições sociais relacionais e coletivas em suas identidades. Por exemplo, o aspecto coletivo da identidade de uma pessoa religiosa pode fazê-la sentir-se valorizada quando age honestamente. Então, mesmo quando confrontada com uma situação em que expressar-se é confortável para sua relação com sua religião (identidade coletiva), essa pessoa pode ter uma tendência mais forte para expressar suas ideias (HOOD JUNIOR, SPILKA, HUNSBERGER et al., 1996).

Em resumo, indivíduos negociam suas identidades nas interações sociais, e eu argumento que essas identidades são mantidas ou alteradas nas interações sociais por meio da adoção de comportamentos no contexto organizacional, como voz e silêncio. Falar ou permanecer calado sobre questões relevantes no trabalho pode contribuir para o reforço do senso de self de um indivíduo (ASHFORD e BARTON, 2007). No entanto, em algumas situações em que o comportamento de um indivíduo não se alinha à expectativa que outros significativos possam ter, seu senso de autoestima pode ser afetado. A seguir, forneço uma explicação para esse processo, que é chamado de ameaça à identidade (KREINER e SHEEP, 2009).

\section{Ameaças a identidades: como indivíduos lidam com elas?}

Ameaças à identidade são "experiências avaliadas como indicativas de dano potencial ao valor, significados e representação de uma identidade" (PETRIGLIERI, 2011, p. 644). Proponho que quando um indivíduo enfrenta uma situação na qual o ato de falar é interpretado como potencialmente prejudicial ao seu senso de autoestima, esse indivíduo enfrenta uma ameaça de identidade. Para uma melhor explicação da definição escolhida, a seguir, esclareço os dois aspectos principais que estão presentes nessa definição.

A expressão "experiências avaliadas como indicativas de dano potencial" sugere que o lócus da ameaça de identidade não é(são) o(s) indivíduo(s) ameaçador(es), mas o indivíduo ameaçado. Um indivíduo pode interpretar uma situação como uma ameaça de identidade, e é a sua posição de interpretador que é a central nesse processo (PETRIGLIERI, 2011); isso implica, por exemplo, que o comportamento de um líder em uma reunião não possa ser classificado, por si, como uma ameaça de identidade. Para caracterizar um comportamento como uma ameaça de identidade, o indivíduo a quem esse comportamento é direcionado precisa interpretar a experiência como um dano potencial à sua identidade (SMITH, 1991). Assim, indivíduos avaliam o significado de um determinado evento com base em seu bem-estar (PETRIGLIERI, 2011), decidem como classificarão o evento e, depois, como responderão a ele (SMITH, 1991). O fato de os indivíduos avaliarem as ameaças à identidade de maneira diferente é geralmente explicado pelo termo sensibilidade à ameaça à identidade (ou sensibilidade à ameaça), que se refere à tendência de um indivíduo de interpretar as experiências de conflito como potencialmente prejudiciais para si (SLUSS e ASHFORTH, 2007). Isso significa dizer que a mesma experiência pode ser interpretada como positiva ou neutra por um indivíduo, mas como altamente ameaçadora por outro (LEAVITT e SLUSS, 2015).

Tendo discutido o significado de uma ameaça de identidade, concluo a revisão da literatura explorando como os indivíduos lidam com ameaças de identidade. Quando eles avaliam uma experiência como prejudicial ao seu senso de autovalor, tendem a negar a ameaça com a adoção de respostas antecipadas de enfrentamento. Essas respostas de enfrentamento são esforços cognitivos e comportamentais que visam reduzir a gravidade dos danos à identidade de uma pessoa (SMITH, 1991). Petriglieri (2011) categorizou dois tipos diferentes de respostas antecipadas de enfrentamento (ou respostas a ameaças) com base em sua função: respostas de preservação e reestruturação de identidade. As respostas de preservação de identidade têm como alvo a fonte do dano potencial e não envolvem alterações na identidade ameaçada. Todavia, essas respostas de 
enfrentamento nem sempre são bem-sucedidas, e o indivíduo pode acreditar que uma ameaça de identidade é insolúvel sob a condição da autodefinição existente (LEAVITT e SLUSS, 2015). Uma resposta alternativa de enfrentamento nesse caso é a adoção de respostas de reestruturação de identidade, que visam à transformação de um aspecto da identidade ameaçada para restabelecer a estabilidade do eu (ASHFORTH, 2001).

Neste artigo, integro a perspectiva micro de CO sobre voz e o silêncio dos funcionários e a literatura de identidade para desenvolver um modelo para explorar os motivos relacionados ao self que levam à escolha de falar ou permanecer em silêncio no trabalho. Na seção seguinte, introduzo as duas questões que orientaram a construção do modelo e orientaram a lógica de sua apresentação.

Pergunta 1: Como os funcionários usam a voz e o silêncio como respostas a ameaças de identidade relacionadas à voz no trabalho?

Pergunta 2: Quais são as condições que influenciam a maneira como os indivíduos respondem às ameaças de identidade relacionadas à voz?

\section{Um modelo baseado em identidade de voz e silêncio dos funcionários}

Com base na revisão que apresentei na literatura sobre voz/silêncio e identidade dos funcionários, apresento o modelo teórico desenvolvido neste estudo na Figura 1. Tal modelo é apresentado por meio de um conjunto de proposições que explicam como o senso de autoestima de um indivíduo pode ser uma força motriz em relação à decisão de oferecer informações voluntárias no trabalho. Tais proposições são representadas por termos que vão de P1 a P5b.

Figura 1

Um modelo baseado em identidades para o silêncio e voz de empregados

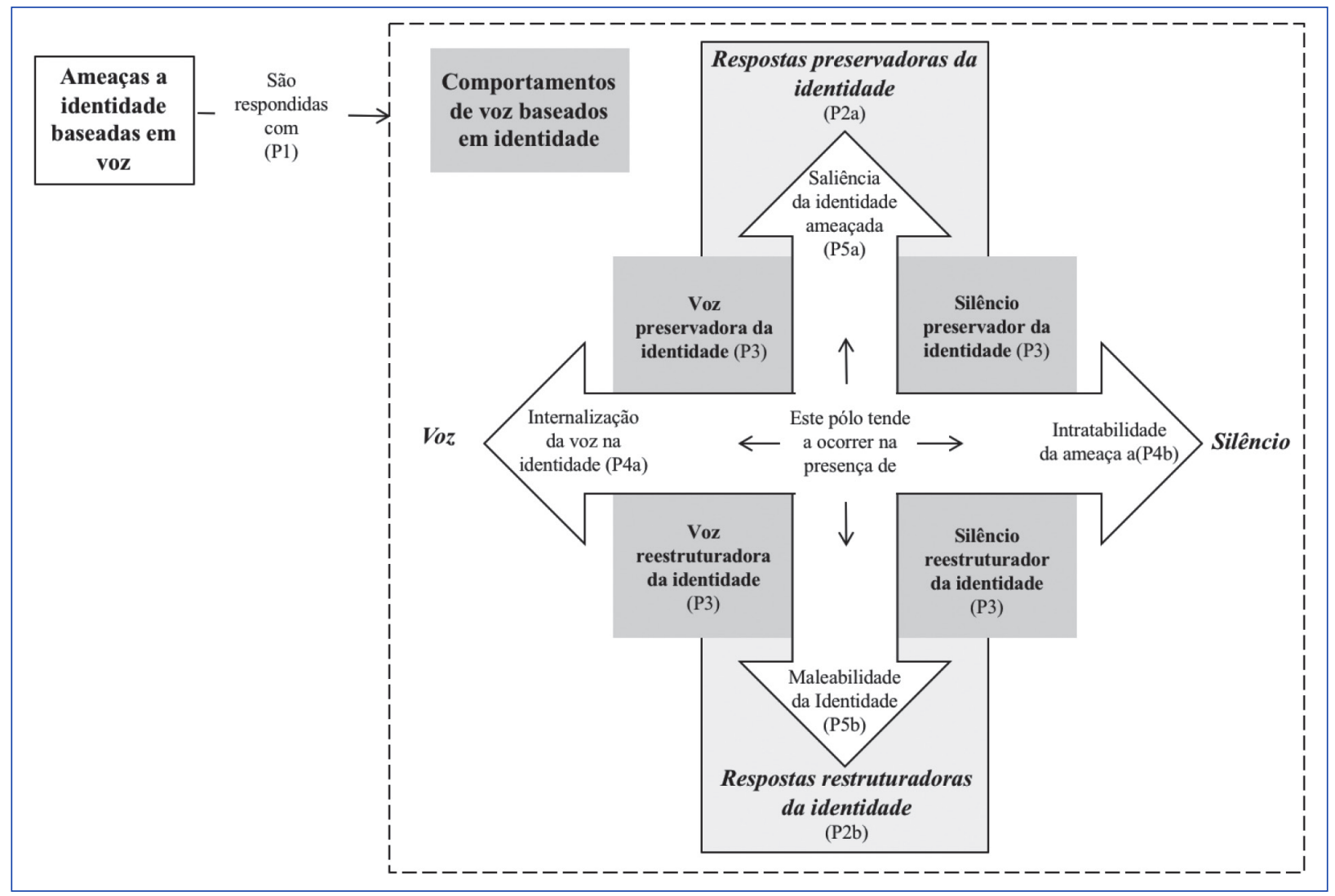

Fonte: Elaborada pelo autor. 


\section{Respostas a ameaças à identidade}

Para responder à primeira pergunta (Como as pessoas usam a voz e o silêncio como respostas a ameaças de identidade relacionadas à voz no trabalho?), começo teorizando que, quando um funcionário sente dúvidas sobre se deve compartilhar uma ideia relevante no trabalho, o que chamo de conflito de voz, essa dúvida pode às vezes ser motivada por uma preocupação com o impacto da decisão de se manifestar sobre seu autovalor. Conforme afirmado por Ashford e Barton (2007), essa decisão não se baseia apenas em uma avaliação racional e explícita da eficiência percebida e da segurança da voz, mas também em uma preocupação com o impacto da decisão da voz no self. Quando isso acontece, é estabelecida uma ameaça de identidade relacionada à voz, que é uma experiência intersubjetiva na qual os indivíduos questionam se o ato de expressar informações relevantes por razões organizacionais pode prejudicar o valor, o significado e a representação de suas identidades no futuro. Assim, esse tipo de ameaça é distinto daquele que é mais comumente descrito na literatura de voz, na medida em que o foco da dúvida não é apenas cognitivo, mas também emocional. Embora as ameaças de identidade relacionadas à voz sejam um fenômeno social, suas repercussões são centradas no self.

Quando uma ameaça de identidade relacionada à voz é avaliada pelo funcionário como algo que indica dano potencial ao senso de autoestima do indivíduo, ela pode ser classificada como uma forma de ameaça à identidade. Nesse caso, ao questionar se devem oferecer informações voluntariamente, indivíduos avaliam: a) se seu senso de valor próprio será desvalorizado no futuro (valor); b) se a associação entre a identidade e seus significados será possível no futuro (significado) e c) se eles serão capazes de representar a identidade em outras interações no futuro (representação). Assim, todos os critérios sugeridos por Petriglieri (2011) para caracterizar uma ameaça de identidade se aplicam a esses conflitos de voz.

Esta teorização é importante porque a presença de um componente relacionado a identidades em um conflito de voz influencia a maneira como os indivíduos responderão a ele. A abordagem calculativa/instrumental para conflitos de voz sugere que os comportamentos relacionados à voz, sejam de expressão ou não, geralmente são estratégicas intencionais e focadas em maximizar ganhos pessoais e minimizar perdas, o que é razoável quando o conflito de voz é causado apenas por questões instrumentais/calculativas (DETERT e BURRIS, 2007). É razoável que a maioria dos comportamentos de voz e silêncio explorados na literatura sejam estratégicos. Contudo, quando o conflito de voz é causado por questões relacionadas ao self, faz sentido sugerir que eles ativem outros tipos de comportamentos de voz e silêncio como respostas (ASHFORD e BARTON, 2007). Eu chamo essas respostas de comportamentos de voz baseados em identidade.

Assim, proponho o seguinte:

Proposição 1: As ameaças de identidade relacionadas à voz são respondidas com respostas de voz baseadas em identidade, e não com respostas de voz instrumentais/calculativas.

Proponho que as respostas de voz baseadas em identidade sejam compostas de duas dimensões bipolares. A primeira dimensão (veja o eixo vertical na Figura 1) é o tipo de resposta que os funcionários apresentarão. Como um conflito de voz baseado em identidade pode ser classificado como uma ameaça de identidade, recorro à literatura de respostas para ameaças de identidade a fim de responder a essa pergunta.

Fundamento-me na classificação de Petriglieri (2011) de respostas antecipadas de enfrentamento a ameaças de identidade para sugerir dois grupos de motivos de possíveis respostas de ameaças com base em suas funções: respostas de proteção da identidade e respostas de reestruturação da identidade. Enquanto o primeiro não envolve mudanças na identidade ameaçada, o segundo exige uma transformação em algum aspecto ameaçado do self. Então:

Proposição 2: Quando indivíduos experimentam ameaças de identidade relacionadas à voz, eles podem adotar: P2a) respostas de preservação da identidade, que não envolvem alterações na identidade do funcionário; ou P2b) respostas de reestruturação da identidade, que envolvem a transformação de algum aspecto da identidade ameaçada.

Conquanto as respostas de reestruturação da identidade às ameaças de identidade relacionadas à voz possam ser intuitivamente associadas ao ato de expressar-se, uma resposta de preservação da identidade pode estar também associada ao silêncio. Teorizo que tanto voz como silêncio são estratégias possíveis para indivíduos que decidem preservar ou reestruturar suas identidades. É importante esclarecer que entendo a voz como o ato de vocalizar as informações relevantes em questão. Assim, como os indivíduos podem não vocalizar seus problemas, conforme ilustrado na Figura 1, os polos que representam essa dimensão são voz e silêncio. Isso está de acordo com a posição explicada anteriormente adotada neste artigo, na qual 
vejo voz e silêncio como polos opostos ao longo de um continuum (ASHFORD, SUTCLIFFE e CHRISTIANSON, 2009; CULLINANE e DONAGHEY, 2014; MORRISON, 2011). Apesar de entender que é possível considerar a existência de 'falar em silêncio' ou 'dizer sem dizer', aqui adoto uma abordagem verbal para o uso dos termos voz e silêncio.

Juntas, essas duas dimensões (tipos de respostas de enfrentamento no eixo vertical e decisão de voz no eixo horizontal) formam quatro quadrantes, cada um dos quais representa uma motivação (preservar ou reestruturar uma identidade) para a escolha de respostas de voz ou silêncio do empregado.

- A voz preservadora da identidade refere-se ao ato de expressar informações relevantes sem transformar a identidade do funcionário. Isso requer a capacidade de retratar a ideia apresentada como complementar, e não incompatível com o aspecto do eu que pode ser ameaçado pelo ato de expressar-se. Exemplo: um funcionário com uma identidade proeminente 'pró-gerenciamento' deseja reclamar de uma prática organizacional que ele considera injusta com seus colegas. No entanto, ele entende que compartilhar essa opinião abertamente afetará seu senso de autoestima, pois contradiz uma identidade valorizada pelo grupo. Assim, ele tenta expressar sua percepção de injustiça, sustentando que, ao corrigir essa prática, a organização poderá obter um melhor desempenho. Assim, o indivíduo compartilha sua percepção sob uma estrutura de argumentação que visa preservar sua identidade pró-gestão.

- A voz reestruturadora da identidade refere-se ao ato de expressar informações relevantes de forma que haja uma mudança na identidade do funcionário. Nessa forma de voz, o indivíduo assume o risco de ser desvalorizado no processo de reconstruir sua identidade. Aqui, manifestar-se é o ato de expressar uma ideia, e também envolve a reconstrução da identidade. Exemplo: na mesma situação apresentada anteriormente, o indivíduo decide compartilhar abertamente sua percepção. Ele sabe que essa autoexposição ameaçará sua 'identidade pró-gestão'. Nesse caso, o senso de autoestima é promovido no sentido de que alguns funcionários 'independentes' aplaudem essa iniciativa, o que pode levar esse indivíduo à construção de uma nova identidade saliente 'independente'.

- O silêncio preservador da identidade refere-se ao ato de reter informações relevantes de maneira a preservar a identidade ameaçada. Nesse caso, o indivíduo finge que nada está ocorrendo e decide assumir os custos da inautenticidade resultante. Por exemplo, na mesma situação de exemplo, o indivíduo decide não expressar sua percepção, preservando assim sua identidade de 'pró-gestão'.

- O silêncio reestruturador da identidade refere-se ao ato de ocultar informações relevantes de tal maneira que outros possam questionar se o silêncio é causado por uma mudança na identidade do indivíduo. Essa resposta é uma forma dramatúrgica de falar por omissão, com o objetivo de fazer com que outros percebam que há algo a ser dito. Por exemplo, nesse caso, o funcionário apresentado anteriormente optaria por não verbalizar sua opinião, mas com uma intenção diferente daquela encontrada no silêncio de preservação de identidade. $O$ indivíduo 'prógestão' pretende chamar a atenção, omitindo sua opinião em uma situação na qual sua identidade social faz com que outros esperem que ele fale em favor do ponto de vista organizacional.Porém, através de seu silêncio, o indivíduo quebra essas expectativas e gera especulações sobre a possibilidade de ele agora estar adotando uma perspectiva 'independente' e crítica.

Assim, sugiro o seguinte:

Proposição 3: Voz e silêncio são respostas através das quais os indivíduos podem manifestar sua vontade de preservar ou reestruturar uma identidade.

\section{Condições que influenciam as respostas às ameaças à identidade}

Quais são as condições que influenciam as respostas que os indivíduos adotam para decisões de voz baseadas em identidade? Recorro a pesquisas anteriores sobre voz e silêncio e identidades sociais de funcionários para propor explicações sobre as características relacionadas à identidade que os indivíduos podem ter e que influenciam suas opções de voz, silêncio e respostas de preservação e reestruturação de identidade a ameaças de identidade relacionadas à voz.

\section{Condições para a voz e o silêncio}

Começo explorando a opção pela voz. Sugiro que indivíduos que internalizam uma proscrição profissional de voz em sua personalidade tendem a usar a voz (seja uma voz de preservação ou de reestruturação de identidade) como resposta a ameaças de identidade relacionadas à voz. Traços de personalidade (LEPINE e VAN DYNE, 2001) e preferências de estilo cognitivo (JANSSEN, DE VRIES e COZIJNSEN, 1998), por exemplo, podem influenciar a noção de comportamento de voz como 
fonte de distinção pessoal. Essa evidência sugere que indivíduos com níveis mais altos de extroversão e consciência tendem a se ver positivamente quando adotam comportamentos de voz. O comportamento e a personalidade de um líder também podem influenciar um indivíduo a oferecer informações com mais frequência no trabalho (DETERT e BURRIS, 2007). É possível sugerir que indivíduos com identidades relacionais altamente salientes imitam o comportamento de seu líder e depois nutrem sua relação com ele pelo ato de falar no trabalho. Por sua vez, o nível coletivo do eu pode provocar uma internalização de comportamentos pró-voz devido à influência da cultura organizacional (DUTTON, ASHFORD, LAWRENCE et al., 2002), percepção de papéis (VAN DYNE, KAMDAR e JOIREMAN, 2008) estruturas e mecanismos coletivos pró-voz (MORRISON e MILLIKEN, 2000). Sugiro que indivíduos com identidades coletivas altamente salientes que possuem uma proscrição pró-voz internalizada tendam a se expressar, tornando-se um membro prototípico do coletivo. Por isso, proponho que:

Proposição 4a: A internalização de uma proscrição pró-voz na personalidade de uma pessoa aumenta as chances de que elas adotem a voz como resposta a ameaças à identidade relacionadas à voz.

A seguir, analiso as condições nas quais tende a ocorrer a decisão do silêncio. Eu teorizo que o silêncio é geralmente adotado quando os indivíduos interpretam que falar em público comprometerá seu senso de valor próprio. A voz reestruturadora da identidade é sustentável apenas se o indivíduo encontrar apoio afetivo em relação à identidade emergente que está contida no conteúdo do que é dito. Quando os funcionários não conseguem obter esse apoio, tendem a optar pelo silêncio. Em outras palavras, sustento que a percepção de intratabilidade de ameaças - a interpretação de que uma "ameaça de identidade é insolúvel nas condições existentes" (LEAVITT e SLUSS, 2015, p. 597) - aumenta a probabilidade de empregados optarem pelo silêncio. Os conflitos de voz, quando avaliados como ameaças de identidade, geram sofrimento psicológico, o que motiva indivíduos a tentar eliminar tais sentimentos por meio de estratégias deliberadas e iterativas (PETRIGLIERI, 2011). Em tais situações, os indivíduos podem, por exemplo, tentar se convencer imaginativamente de que falar não prejudicará seu senso de autoestima. $\mathrm{O}$ uso do trabalho de identidade, uma estratégia de enfrentamento na qual o indivíduo 'gira a identidade' para ressignificá-la em direção a uma interpretação mais favorável, alinhada ao seu próprio senso específico de self, é um exemplo dessa estratégia (LEAVITT e SLUSS, 2015). No entanto, quando ocorre a percepção de que essas estratégias de gerenciamento de significado de identidade não funcionam e que a divulgação tornará insustentável a representação de uma identidade destacada no futuro, a ameaça de identidade relacionada à voz é interpretada como intratável, e o silêncio é escolhido. Desta forma, teorizo o seguinte:

Proposição 4b: A intratabilidade da ameaça aumenta a probabilidade de que empregados adotem o silêncio como resposta a ameaças à identidade relacionadas à voz.

\section{Condições em que ocorrem as respostas e preservadoras e reestruturadoras da identidade}

Sugiro que as respostas de preservação da identidade às ameaças de identidade relacionadas à voz (voz ou silêncio preservador da identidade) têm maior probabilidade de ocorrer quando a identidade ameaçada é altamente saliente para o funcionário. Quanto mais central é a identidade para o senso de self, menos os indivíduos tendem a colocar em risco o aspecto de seu autovalor que é derivado dessa identidade (ASHFORTH, 2001). Assim, se o aspecto do eu que está ameaçado na possível comunicação de uma ideia relevante no trabalho for saliente na composição identitária de um funcionário, ele provavelmente evitará respostas que os exponham à rejeição e desaprovação. Nesse caso, o funcionário escolhe uma resposta de enfrentamento que não envolve alterações na identidade ameaçada. Proponho, então, o seguinte:

Proposição 5a: A sailência de identidade ameaçada aumenta a probabilidade de que um empregado adote uma voz ou silêncio preservador da identidade como resposta às ameaças à identidade relacionadas à voz.

Por sua vez, argumento que é mais provável que as respostas à reestruturação da identidade ocorram quando o indivíduo apresenta maior maleabilidade da identidade. As respostas à reestruturação da identidade são baseadas em uma tentativa, explícita ou implícita, de abandonar a identidade que está relacionada ao eu socialmente desejado. Isso só é possível porque as identidades são dinâmicas e multifacetadas, apesar de razoavelmente estáveis (MARKUS e WURF, 1987; PETRIGLIERI, 2011). Assim, as identidades têm a propriedade de serem maleáveis. Todavia, os indivíduos podem mostrar diferentes graus de maleabilidade de suas identidades. Alguns funcionários podem estar mais abertos a saídas de identidade do que outros (LEAVITT e SLUSS, 2015), e sugiro que essa abertura para alternar entre identidades que melhor promovam o senso 
de autoestima aumenta a probabilidade de que a reestruturação de identidade seja escolhida como resposta a ameaças de identidade relacionadas à voz. Portanto:

Proposition 5b: A maleabilidade da identidade aumenta a probabilidade de que empregados adotem voz ou silêncio restruturadores da identidade como respostas a ameaças à identidade relacionados à voz.

Na Figura 2, eu apresento um sumário das condições para para cada resposta de voz baseada em identidades baseadas nas Proposições 4a-5b, o que leva a um melhor entendimento das circunstâncias nas quais cada resposta possui maior probabilidade de ocorrer.

Figura 2

Condições que influenciam as respostas a ameaças a identidades identity threats

\begin{tabular}{|c|c|c|c|}
\hline \multirow{4}{*}{ Voz } & Respostas preser & ras da identidade & \multirow{4}{*}{ Silêncio } \\
\hline & $\begin{array}{l}\text { Voz preservadora da } \\
\text { identidade } \\
\text { tende a ocorrer na presença de } \\
\text { - Alta internacionalização de } \\
\text { uma proscrição pró voz na } \\
\text { personalidade dos indivíduos } \\
\text { - Alta saliência da identidade } \\
\text { ameaçada }\end{array}$ & $\begin{array}{l}\text { Silêncio preservador da } \\
\text { identidade } \\
\text { tende a ocorrer na presença de } \\
\text { - Interpretações de que a } \\
\text { identidade é intratável } \\
\text { - Alta saliência da identidade } \\
\text { ameaçada }\end{array}$ & \\
\hline & $\begin{array}{c}\text { Voz reestruturadora da } \\
\text { identidade } \\
\text { tende a ocorrer na presença de } \\
\text { - Alta internacionalização de } \\
\text { uma proscrição pró voz na } \\
\text { personalidade dos indivíduos } \\
\text { - Alta maleabilidade da } \\
\text { identidade }\end{array}$ & $\begin{array}{c}\text { Silêncio reestruturador } \\
\text { da identidade } \\
\text { tende a ocorrer na presença de } \\
\text { - Interpretações de que a } \\
\text { identidade é intratável } \\
\text { - Alta maleabilidade da } \\
\text { identidade }\end{array}$ & \\
\hline & \multicolumn{2}{|c|}{ Respostas reestruturadoras da identidade } & \\
\hline
\end{tabular}

Fonte: Elaborada pelo autor.

Após apresentar o modelo baseado em identidades para a voz e o silêncio de empregados, no próximo tópico, eu discuto as principais contribuições deste modelo para a literatura, sugiro direções para futuras pesquisas e apresento as implicações práticas do modelo para organizações e trabalhadores.

\section{Discussão}

Voz e silêncio dos funcionários, a despeito de serem construtos amplamente explorados, são subteorizados no que tange ao comportamento cotidiano no local de trabalho. Este trabalho se insere nessa lacuna, teorizando que a voz e o silêncio dos funcionários são: a) comportamentos sociofuncionais incorporados nas interações no local de trabalho; e b) respostas a uma ameaça de identidade que ocorre quando um indivíduo questiona se expressar informações relevantes prejudicaria seu senso de identidade. Através da adoção de uma lente teórica de identidades, que permite conectar ações individuais e estruturas sociais baseadas em papéis, este estudo contribui para a literatura de voz e silêncio dos funcionários, são fornecidos insights 
teóricos que só poderiam emergir de uma perspectiva interdisciplinar sobre os motivos pelos quais pessoas decidem expressar sua voz. Este trabalho responde à recente chamada para um desenvolvimento teórico mais integrador a respeito da voz e do silêncio dos funcionários (KLAAS, OLSON-BUCHANAN e WARD, 2012).

A principal contribuição desta pesquisa para a literatura de voz do OB é acrescentar a identidade como um dos motivos para o ato de expressar-se ou permanecer em silêncio no trabalho. Esses motivos são complementares à abordagem instrumentalcalculativa que domina a literatura. Este artigo estende os estudos anteriores que propuseram abordagens não calculativas para a voz dos funcionários, como o estudo de Ashford e Barton (2007) sobre como identidade influencia a proposição de resolução de problemas nas organizações e o estudo de Detert e Edmondson (2011) sobre as teorias implícitas da voz. O modelo apresentado mostra um processo psicológico implícito e menos intencional que visa proteger o senso de autoestima de um indivíduo, enquanto ele decide se deve compartilhar informações voluntariamente. O trabalho também introduz fatores individuais e contextuais que influenciam a maneira como os indivíduos avaliam um conflito de voz baseado em identidade e as condições que influenciam as estratégias de enfrentamento que os indivíduos usam para responder a eles.

Este estudo tem implicações para as disposições que empregados possuem para manifestarem ou não informações relevantes no trabalho. Embora estudos anteriores tenham sugerido que os indivíduos respondem aos sinais do ambiente em que trabalham ao avaliar a decisão de compartilhar ideias e preocupações (DUTTON, ASHFORD, LAWRENCE et al., 2002; STAMPER e VAN DYNE, 2001), independentemente do contexto, alguns indivíduos são mais inclinados a oferecerem informações voluntárias que outras (MORRISON, 2011). Fatores como sentimentos de eficácia dos indivíduos (TANGIRALA e RAMANUJAM, 2008), preferências de personalidade e estilo cognitivo (JANSSEN, DE VRIES e COZIJNSEN, 1998) mostraram-se como antecedentes dos comportamentos vocais no trabalho em pesquisas anteriores. Entretanto, nesta pesquisa apresentei um antecedente individual inexplorado na literatura: a sensibilidade a ameaças de identidade, que é a tendência de um indivíduo a interpretar um conflito como potencialmente prejudicial para seu self (SLUSS e ASHFORTH, 2007). Afirmei que as ameaças de identidade relacionadas à voz são respondidas com respostas de voz baseadas em identidade. Em outras palavras, os indivíduos que são mais vulneráveis em seu senso de autoestima tendem a adotar as quatro respostas de voz baseadas em identidade apresentadas neste artigo. Esse é um importante avanço teórico para a literatura sobre voz e silêncio dos funcionários, pois retrata essas decisões como comportamentos sociofuncionais que ajudam os indivíduos a navegar socialmente. Assim, explicamos como eles enfrentam situações de conflito no trabalho de forma a se verem de uma maneira positiva e promovendo sua distintividade pessoal.

Esta pesquisa também contribui para a literatura de RI sobre voz e silêncio dos funcionários. Estudos em nível micro sobre voz geralmente ignoram o contexto externo das organizações, e isso as leva a uma suscetibilidade a um viés etnocêntrico, porque grande parte do poder explicativo pode derivar de fatores que dependem da cultura (KAUFMAN, 2015). Hoption, Christie e Barling (2008) sugeriram que a voz e o silêncio dos funcionários devem ser teorizados com a ideia de que as organizações são sistemas abertos que influenciam e são influenciados pelo que acontece no ambiente econômico, jurídico e cultural. No modelo apresentado, as ameaças de identidade relacionadas à voz não são interpretadas como um fenômeno que se origina do indivíduo ameaçador, mas do indivíduo ameaçado. Isso significa que, embora o comportamento de outras pessoas possa estimular ou desencorajar a emissão de opiniões, é o indivíduo que está refletindo sobre se deve se manifestar ou não que verá a situação como ameaçadora (PETRIGLIERI, 2011). Esse julgamento, no entanto, pode ser fortemente influenciado pelo fato de a economia estar em expansão ou em recessão, se a lei em um país promove a estabilidade de um funcionário, se as organizações podem facilmente demitir funcionários e se o sistema cultural tem uma distância de poder alta ou baixa, por exemplo. Em economias em recessão, nas quais as organizações podem facilmente mudar de trabalhadores permanentes para trabalhadores temporários, e em culturas com alta distância de poder, os indivíduos provavelmente mostrarão maior sensibilidade às ameaças e, então, terão mais chances de adotar respostas de voz baseadas em identidade.

\section{Pesquisas futuras}

Esse modelo baseado em identidade sobre voz e silêncio dos funcionários oferece respostas preliminares sobre como o senso de self de um indivíduo pode influenciar a decisão de falar ou permanecer em silêncio no trabalho e também abre novos caminhos para explorar esse problema em estudos futuros. Primeiro, os pesquisadores podem investigar os efeitos da adoção de cada uma das quatro respostas baseadas em identidade ao longo do tempo no senso de self do indivíduo. 0 trabalho de identidade é um processo contínuo (LEAVITT e SLUSS, 2015); como tal, futuras pesquisas longitudinais poderiam explorar padrões a respeito de como a voz ou o silêncio baseado em identidade levam a outros comportamentos e das consequências da adoção recorrente de uma das táticas descritas. É possível que a voz reestruturadora da identidade possa 
exigir comportamentos adicionais quando ocorrerem conflitos de voz subsequentes para proteger ou sustentar a identidade emergente que foi revelada em sua reestruturação. Também seria interessante elucidar as conseqüências da adoção da voz preservadora da identidade para a autoestima, uma vez que pesquisas anteriores examinaram os resultados negativos produzidos pelo sentimento de falta de autenticidade gerado por essas estratégias.

Segundo, estudos poderiam explorar a influência de motivos baseados em identidades nas características individuais que aumentam a probabilidade de os indivíduos optarem por falar ou não. Por exemplo, como pesquisas anteriores sugeriram que extrovertidos atribuem maior importância à atenção social (ASHTON, LEE e PAUNONEN, 2002), esses indivíduos provavelmente são mais suscetíveis a ameaças de identidade relacionadas à voz. Além disso, existem evidências de que indivíduos com altos níveis de amabilidade tendem a adotar uma abordagem social para o comportamento (LEIKAS e LINDEMAN, 2009) e a identificar ameaças de identidade nas interações cotidianas.

Terceiro, embora a voz seja intuitivamente associada a uma resposta de reestruturação de identidade a ameaças de identidade, e o silêncio possa ser considerado uma resposta de preservação de identidade, este artigo propõe que os indivíduos possam reestruturar sua identidade através do silêncio ou preservá-la por meio da voz. Portanto, essas duas formas contraintuitivas de voz baseada em identidade precisam de uma exploração adicional, para que possamos entender melhor as táticas adotadas pelos indivíduos quando eles querem falar em silêncio ou falar sem prejudicar o eu atual. Seria particularmente relevante explorar a comunicação não verbal que ocorre durante o silêncio reestruturador da identidade e as estruturas paradoxais semânticas da voz preservadora da identidade.

\section{Implicações Práticas}

Esta pesquisa tem implicações para funcionários, líderes, organizações e sindicatos. O modelo apresentado pode ajudar os funcionários a se tornarem mais conscientes de suas decisões de voz ou ao silêncio no trabalho, pois frequentemente vivenciam ameaças de identidade relacionadas à voz. Ao reconhecer a dinâmica de voz/silêncio e de preservação/reestruturação da identidade, os funcionários podem evitar padrões não intencionais e indesejados em suas respostas de enfrentamento. Por sua vez, os líderes podem refletir sobre como a maneira como se relacionam pode pressionar seus subordinados a se comportarem de uma maneira específica. Por exemplo, é possível que a pressão excessiva dos líderes pela proatividade e autossuficiência dos funcionários silencie os subordinados que desejam expressar que a equipe precisa de mais treinamento, mas temem ser rotulados pelo líder como muito reativos ou dependentes do apoio organizacional. As organizações e os sindicatos também devem prestar atenção ao tipo de pressão que aplicam e se essas pressões representam ameaças à identidade dos funcionários. Neste caso, recomendo que as organizações trabalhem no desenvolvimento de uma imagem coletiva que seja interpretada como pró-voz, o que tende a aumentar o sucesso dos mecanismos de voz. Além disso, sugiro que os sindicatos trabalhem para o desenvolvimento de uma imagem coletiva que pareça mais atraente para os indivíduos, porque a decisão de se envolver nessa forma de voz também pode ser influenciada por questões de identidade. Isso, no entanto, exigiria uma profunda reflexão sobre o significado que é institucionalmente associado à voz sindical em um sentido mais amplo. 


\section{REFERÊNCIAS}

ASHFORD, S. J.; BARTON, M. A. Identity-based issue selling. In: BARTEL, C. A.; BLADER, S.; WRZESNIEWSKI, A. (Eds.). Identity and The Modern Organization. New York: Psychology Press, 2007.

ASHFORD, S. J.; SUTCLIFFE, K. M.; CHRISTIANSON, M. K. Speaking up and speaking out: the leadership dynamics of voice in organizations. In: GREENBERG, J.; EDWARDS, M. S. (Eds.). Voice and Silence in Organizations. Bingley: Emerald, 2009.

ASHFORTH, B. Role transitions in organizational life: an identitybased perspective. London: Routledge, 2001.

ASHTON, M. C.; LEE, K.; PAUNONEN, S. V. What is the central feature of extraversion? Social attention versus reward sensitivity. Journal of Personality and Social Psychology, v. 83, n. 1, p. 245-252, 2002. Disponível em: <http://doi.org/10.1037/0022-3514.83.1.245>. Acesso em: 03 set. 2019.

BREWER, M. B.; GARDNER, W. Who is this "we"? Levels of collective identity and self representations. Journal of Personality and Social Psychology, v. 71. n. 1, p. 83-93, 1996. Disponível em: <http://doi. org/10.1037/0022-3514.71.1.83>. Acesso em: 03 set. 2019.

BRINSFIELD, C. T. Employee silence motives: investigation of dimensionality and development of measures. Journal of Organizational Behavior, v. 34, n. 5, p. 671-697, 2013. Disponível em: <http://doi. org/10.1002/job.1829>. Acesso em: 03 set. 2019.

BUDD, J. W. The future of employee voice. In: WILKINSON, A. et al. (Eds.). The handbook of research on employee voice: participation and involvement in the workplace. Cheltenham: Elgar Press, 2014.

BURRIS, E. R. The risks and rewards of speaking up: managerial responses to employee voice. Academy of Management Journal, v. 55, n. 4, p. 851-875, 2012. Disponível em: <http://doi.org/10.5465/ amj.2010.0562>. Acesso em: 03 set. 2019.

BURRIS, E. R.; DETERT, J. R.; CHIABURU, D. S. Quitting before leaving: the mediating effects of psychological attachment and detachment on voice. Journal of Applied Psychology, v. 93. n. 4, p. 912-922, 2008. Disponível em: <http://doi.org/10.1037/0021-9010.93.4.912>. Acesso em: 03 set. 2019.

CHAMBERLIN, M.; NEWTON, D. W.; LEPINE, J. A. A meta-analysis of empowerment and voice as transmitters of high-performance managerial practices to job performance. Journal of Organizational Behavior, v. 39, n. 10, p. 1296-1313, 2018. Disponível em: <http:// doi.org/10.1002/job.2295>. Acesso em: 03 set. 2019.

CHIU, C. Y.; HONG, Y. Y.; DWECK, C. S. Lay dispositionism and implicit theories of personality. Journal of Personality and Social Psychology, v. 73, n. 1, p. 19-30, 1997. Disponível em: <http://doi.org/10.1037/00223514.73.1.19>. Acesso em: 03 set. 2019.

CONROY, S. A.; O'LEARY-KELLY, A. M. Letting go and moving on: workrelated identity loss and recovery. Academy of Management Review, v. 39, n. 1, p. 67-87, 2014. Disponível em: <http://doi.org/10.5465/ amr.2011.0396>. Acesso em: 03 set. 2019.

COOPER, D.; THATCHER, S. M. B. Identification in organizations: the role of self-concept orientations and identification motives. Academy of Management Review, v. 35, n. 4, p. 516-538, 2010. Disponível em: <http://doi.org/10.5465/AMR.2010.53502693>. Acesso em: 03 set. 2019.
CULLINANE, N.; DONAGHEY, J. Employee silence. In: WILKINSON, A. et al. (Eds.). Handbook of research on employee voice. Cheltenham: Edward Elgar, 2014.

DETERT, J. R.; BURRIS, E. R. Leadership behavior and employee voice: is the door really open? Academy of Management Journal, v. 50, n. 4, p. 869-884, 2007. Disponível em: <http://doi.org/10.5465/ AMJ.2007.26279183>. Acesso em: 03 set. 2019.

DETERT, J. R.; EDMONDSON, A. C. Implicit voice theories: taken-forgranted rules of self-censorship at work. Academy of Management Journal, v. 54, n. 3, p. 461-488, 2011. Disponível em: <http://doi. org/10.5465/AMJ.2011.61967925>. Acesso em: 03 set. 2019.

DETERT, J. R.; TREVIÑO, L. K. Speaking up to higher-ups: how supervisors and skip-level leaders influence employee voice. Organization Science, v. 21, n. 1, p. 249-270, 2010. Disponível em: <http://doi.org/10.1287/ orsc.1080.0405>. Acesso em: 03 set. 2019.

DONAGHEY, J. et al. Reconceptualising employee silence: problems and prognosis. Work, Employment \& Society, v. 25, n. 1, p. 51-67, 2011. Disponível em: <http://doi.org/10.1177/0950017010389239>. Acesso em: 03 set. 2019.

DUTTON, J. E.; ASHFORD, S. J. Selling issues to top management. Academy of Management Review, v. 18, n. 3, p. 397-428, 1993. Disponível em: <http://doi.org/10.5465/AMR.1993.9309035145>. Acesso em: 03 set. 2019.

DUTTON, J. E. et al. Red light, greenlight: making sense of the organizational context for issue selling. Organization Science, v. 13, n. 4, p. 335-369, 2002. Disponível em: <http://doi.org/10.1287/ orsc.13.4.355.2949>. Acesso em: 03 set. 2019.

DUTTON, J. E.; ROBERTS, L. M.; BEDNAR, J. Pathways for positive identity construction at work: four types of positive identity and the building of social resources. Academy of Management Review, v. 35, n. 2, p. 265-293, 2010. Disponível em: <http://doi.org/10.5465/ AMR.2010.48463334>. Acesso em: 03 set. 2019.

FELIX, B.; CAVAZOTTE, F. When a calling goes unanswered: exploring the role of workplace personalizations as calling enactments. Frontiers in Psychology, v. 13, p. 1-14, 2019. Disponível em: <https://doi. org/10.3389/fpsyg.2019.01940>. Acesso em: 03 set. 2019.

FELIX, B.; MELLO, A.; VON BORELL, D. Voices unspoken? Understanding how gay employees conconstruct a climate of voice/silence in organisations. The International Journal of Human Resource Management, v. 29, n. 5, p. 805-828, 2018. Disponível em: <http:// doi.org/10.1080/09585192.2016.1255987>. Acesso em: 03 set. 2019.

FRAZIER, M. L.; FAINSHMIDT, S. Voice climate, work outcomes, and the mediating role of psychological empowerment: A multilevel examination. Group \& Organization Management, v. 37, n. 6, p. 691-715, 2012. Disponível em: <http://doi.org/10.1177/1059601112463960>. Acesso em: 03 set. 2019.

GOMES, R.; FELIX, B.. O self no armário: uma teoria fundamentada sobre o silêncio de gays e de lésbicas no ambiente de trabalho. Cadernos EBAPE.BR, Rio de Janeiro, v. 17, n. 2, p. 375-388, 2019. Disponível em: <http://doi.org/10.1590/1679-395174796>. Acesso em: 03 set. 2019. 
GREENBERG, J.; EDWARDS, M. S. Voice and silence in organizations. Bingley: Emerald, 2009.

HARVEY, P.; MARTINKO, M. J.; DOUGLAS, S. C. Causal perceptions and the decision to speak up or pipe down. In: GREENBERG, J.; EDWARDS, M. S. (Eds.). Voice and silence in organizations. Bingley: Emerald, 2009.

HOGG, M. A.; TERRY, D. I. Social identity and self-categorization processes in organizational contexts. Academy of Management Review, v. 25, n. 1, p. 121-140, 2000. Disponível em: <http://doi. org/10.5465/AMR.2000.2791606>. Acesso em: 03 set. 2019.

HOOD JUNIOR, R. et al. The psychology of religion: An empirical approach. New York: Guilford Press, 1996.

HOPTION, C.; CHRISTIE, A.; BARLING, J. Introduction. In: BARLING, J.; COOPER, C. (Eds.). Sage handbook of organizational behavior. London: Sage, 2008.

JANSSEN, O.; DE VRIES, T.; COZIJNSEN, A. J. Voicing by adapting and innovating employees: An empirical study on how personality and environment interact to affect voice behavior. Human Relations, v. 51, n. 7, p. 945-967, 1998.

KAUFMAN, B. E. Theorising determinants of employee voice: An integrative model across disciplines and levels of analysis. Human Resource Management Journal, v. 25, n. 1, p. 19-40, 2015. Disponível em: <http://doi.org/10.1111/1748-8583.12056>. Acesso em: 03 set. 2019.

KLAAS, B. S.; OLSON-BUCHANAN, J.; WARD, A.-K. The determinants of alternative forms of workplace voice: An integrative perspective. Journal of Management, v. 38, n. 1, p. 314-345, 2012. Disponível em: <http://doi.org/10.1177/0149206311423823>. Acesso em: 03 set. 2019.

KNOLL, M.; VAN DICK, R. Do I hear the whistle...? A first attempt to measure four forms of employee silence and their correlates. Journal of Business Ethics, v. 113, n. 2, p. 349-362, 2013. Disponível em: <http://doi.org/10.1007/s10551-012-1308-4>. Acesso em: 03 set. 2019.

KREINER, G. E.; SHEEP, M. Growing pains and gains: Framing identity dynamics as opportunities for identity growth. In: ROBERTS, L. M.; DUTTON, J. E. (Eds.). Exploring positive identities and organizations: building a theoretical and research foundation. New York: Routledge, 2009.

LAM, C. F. et al. Shooting from the hip: a habit perspective of voice. Academy of Management Review, v. 43, n. 3, p. 470-486, 2018. Disponível em: <http://doi.org/10.5465/amr.2015.0366>. Acesso em: 03 set. 2019.

LEAVITT, K.; SLUSS, D. M. Lying for who we are: an identity-based model of workplace dishonesty. Academy of Management Review, v. 40, n. 4, p. 587-610, 2015. Disponível em: <http://doi.org/10.5465/ amr.2013.0167>. Acesso em: 03 set. 2019.

LEIKAS, S.; LINDEMAN, M. Personality, threat identification and emotional processing. European Journal of Personality, v. 23, n. 6, p. 455-474, 2009. Disponível em: <http://doi.org/10.1002/per.713>. Acesso em: 03 set. 2019.

LEPINE, J. A.; VAN DYNE, L. Voice and cooperative behavior as contrasting forms of contextual performance: evidence of differential relationships with big five personality characteristics and cognitive ability. Journal of Applied Psychology, v. 86. n. 2, p. 326-336, 2001.
Disponível em: <http://doi.org/10.1037/0021-9010.86.2.326>. Acesso em: 03 set. 2019.

MARKUS, H.; WURF, E. The dynamic self-concept: a social psychological perspective. Annual Review of Psychology, v. 38, n. 1, p. 299-337, 1987. Disponível em: <http://doi.org/10.1146/ annurev.ps.38.020187.001503>. Acesso em: 03 set. 2019.

MEAD, G. H. Mind, self and society. Chicago: University of Chicago Press, 1934.

MORRISON, E. W. Employee voice behavior: integration and directions for future research. Academy of Management Annals, v. 5, n. 1, p. 373-412, 2011.

MORRISON, E. W.; MILLIKEN, F. J. Organizational silence: a barrier to change and development in a pluralistic world. Academy of Management Review, v. 25, n. 4, p. 706-725. Disponível em: <http:// doi.org/10.5465/AMR.2000.3707697>. Acesso em: 03 set. 2019.

MORRISON, E. W.; WHEELER-SMITH, S. L.; KAMDAR, D. Speaking up in groups: A cross-level study of group voice climate and voice. Journal of Applied Psychology, v. 96, n. 1, p. 183-191, 2011. Disponível em: <http://doi.org/10.1037/a0020744>. Acesso em: 03 set. 2019.

MOWBRAY, P. K.; WILKINSON, A.; TSE, H. H. An integrative review of employee voice: identifying a common conceptualization and research agenda. International Journal of Management Reviews, v. 17, n. 3, p. 382-400, 2015. Disponível em: <http://doi.org/10.1111/ ijmr.12045>. Acesso em: 03 set. 2019.

NG, T. W. H.; FELDMAN, D. C. Employee voice behavior: a metaanalytic test of the conservation of resources framework. Journal of Organizational Behavior, v. 33, n. 2, p. 216-234, 2012. Disponível em: <http://doi.org/10.1002/job.754>. Acesso em: 03 set. 2019.

PETRIGLIERI, J. L. Under threat: responses to and the consequences of threats to individuals' identities. Academy of Management Review, v. 36, n. 4, p. 641-662, 2011. Disponível em: <http://doi.org/10.5465/ amr.2009.0087>. Acesso em: 03 set. 2019.

PINDER, C. C.; HARLOS, K. P. Employee silence: quiescence and acquiescence as responses to perceived injustice. Research in Personnel and Human Resources Management, v. 20, p. 331-369, 2001. Disponível em: <http://doi.org/10.1016/S0742-7301(01)200073>. Acesso em: 03 set. 2019.

PRATT, M. G.; FOREMAN, P. O. The Beauty of and Barriers to Organizational Theories of Identity. Academy of Management Review, v. 25, n. 1, p. 141-152, 2000. Disponível em: <http://doi.org/10.5465/ AMR.2000.27711650>. Acesso em: 03 set. 2019.

SLUSS, D. M.; ASHFORTH, B. E. Relational identity and identification: Defining ourselves through work relationships. Academy of Management Review, v. 32, n. 1, p. 9-32, 2007. Disponível em: <http:// doi.org/10.5465/AMR.2007.23463672>. Acesso em: 03 set. 2019.

SMITH, C. A. The self, appraisal, and coping. In: SNYDER, C. R.; FORSYTH, D. R. (Eds.). Handbook of social and clinical psychology: the health perspective. Elmsford: Pergamon Press, 1991.

STAMPER, C. L.; VAN DYNE, L. Work status and organizational citizenship behavior: a field study of restaurant employees. Journal of Organizational Behavior, v. 22, n. 5, p. 517-536, 2001. Disponível em: <http://doi.org/10.1002/job.100>. Acesso em: 03 set. 2019. 
TANGIRALA, S.; RAMANUJAM, R. Exploring nonlinearity in employee voice: the effects of personal control and organizational identification. Academy of Management Journal, v. 51, n. 6, p. 1189-1203, 2008. Disponível em: <http://doi.org/10.5465/AMJ.2008.35732719>. Acesso em: 03 set. 2019.

VADERA, A. K.; AGUILERA, R. V.; CAZA, B. B. Making sense of whistleblowing's antecedents: Learning from research on identity and ethics programs. Business Ethics Quarterly, v. 19, n. 4, p. 553-586, 2009. Disponível em: <http://doi.org/10.5840/beq200919432>. Acesso em: 03 set. 2019.

VAN DYNE, L. V.; ANG, S.; BOTERO, I. C. Conceptualizing employee silence and employee voice as multidimensional constructs. Journal of Management Studies, v. 40, n. 6, p. 1359-1392, 2003. Disponível em: <http://doi.org/10.1111/1467-6486.00384>. Acesso em: 03 set. 2019.

VAN DYNE, L. V.; KAMDAR, D.; JOIREMAN, J. In-role perceptions buffer the negative impact of low LMX on helping and enhance the positive impact of high LMX on voice. Journal of Applied Psychology, v. 93, n. 6, p. 1195-1207, 2008. Disponível em: <http://doi.org/10.1037/00219010.93.6.1195>. Acesso em: 03 set. 2019.
VROOM, V. H. Work and motivation. New York: Wiley, 1964.

WANG, Y. -D.; HSIEH, H.-H. Organizational ethical climate, perceived organizational support, and employee silence: A cross-level investigation. Human Relations, v. 66, n. 6, p. 783-802, 2013. Disponível em: <http://doi.org/10.1177/0018726712460706>. Acesso em: 03 set. 2019.

WEAVER, G. R.; AGLE, B. R. Religiosity and ethical behavior in organizations: A symbolic interactionist perspective. Academy of Management Review, v. 27, n. 1, p. 77-97, 2002. Disponível em: <http://doi.org/10.5465/AMR.2002.5922390>. Acesso em: 03 set. 2019.

WHITESIDE, D. B.; BARCLAY, L. J. Echoes of silence: Employee silence as a mediator between overall justice and employee outcomes. Journal of Business Ethics, v. 116, n. 2, p. 251-266, 2013. Disponível em: <http://doi.org/10.1007/s10551-012-1467-3>. Acesso em: 03 set. 2019.

WILKINSON, A.; FAY, C. New times for employee voice? Human Resource Management, v. 50, n. 1, p. 65-74, 2011. Disponível em: <http://doi.org/10.1002/hrm.20411>. Acesso em: 03 set. 2019.

Bruno Felix

ORCID: https://orcid.org/0000-0001-6183-009x

Doutor em Administração pela Universidade Presbiteriana Mackenzie; Professor do Programa de Pós Graduação em Administração na Fucape Business School, Vitória-ES, Brasil. E-mail: bfelix@fucape.br 